Revista Eletrônica do Programa de Pós-Graduação em Mídia e Cotidiano

Artigos Seção Livre

Número 1. 109-121 janeiro/abril 2013

(C) 2013 by UFF

\title{
CASAMENTOS-RELÂMPAGO, BUSCA DE SAÚDE \\ E OS ABISMOS DO FLUXO
}

\section{LIGHTNING-QUICK MARRIAGES, SEARCHING FOR HEALTH AND THE ABYSSES OF THE FLOW}

FERNANDA CUPOLILLO ${ }^{1}$

Resumo: O presente artigo busca investigar, a partir do boom dos casamentos-relâmpago de celebridades, os novos tipos de uniões amorosas contemporâneas, marcadamente de curta duração, cujos prazos parecem expirar com base em uma preocupação com a "saúde do relacionamento" e cotações em um mercado das relações. A partir da imersão em um fluxo amoroso, de trocas constantes de parceiros, pretende-se pensar os abismos de sentido nos quais os indivíduos contemporâneos são lançados, assim como a constituição de "redes amorosas”, em que se está ligado a muitos simultaneamente, mesmo que em estado de latência.

Palavras-chave: casamentos-relâmpago; rede amorosa; celebridade.

Abstract: This article aims to investigate, considering the boom in lightning-quick celebrity marriages, the new forms of love bonds, predominantly short-lasting, whose duration seems to expire based on a concern with the "health of the relationship" and rates and prices in a relationship stock market. By immerging in a love flow, one of constant exchanges of partners, one aims to ponder the abysses in sense into which contemporary individuals are cast as well as the building of "love networks", in which they are connected to many, even if only in a latency state.

Keywords: lightning-quick marriages; love network; celebrity.

\footnotetext{
1 Doutoranda em Comunicação/UFF. Desenvolve o projeto: “O papel estratégico das celebridades na reconfiguração contemporânea dos laços amorosos”. Orientadora: Profa. Dra. Paula Sibilia. Graduanda em Psicologia/UFF. Email: fernanda.cupolillo@gmail.com
} 
Casamentos-relâmpago - uma introdução

Uma nova modalidade de casamento, fartamente comentada em revistas de celebridades e programas de auditório da TV, parece estar crescendo, como se pode observar em narrativas que vêm sendo produzidas recorrentemente acerca do mundo dos famosos. Trata-se dos “casamentos-relâmpago”. Chama a atenção o fenômeno deslanchar em meio a um contexto no qual é o próprio casamento que parece estar em crise: acompanha-nos uma vaga (e perturbadora) sensação de instabilidade, vivenciada cotidianamente em diversos espaços sociais nos quais circulamos (sejam "virtuais” ou não), que parece se acender ao formularmos sentenças de ceticismo que reforçam a desconfiança generalizada em relação a essa instituição. Os laços afetivos e familiares nos parecem mais frouxos do que antes ou mesmo líquidos (BAUMAN, 2004) - pelo menos é isso o que escutamos de grande parte das narrativas de indivíduos que nos antecederam no tempo, no que diz respeito à cultura ocidental no contexto do capitalismo. E as pessoas, sobretudo as mais jovens, parecem não mais desejar como antes uma proximidade amorosa que se estenda de um modo necessariamente cansativo no tempo e que, de alguma forma, venha a ameaçar a liberdade e a independência dos envolvidos na parceria - características que, vale dizer, modelam as parcerias amorosa contemporaneamente (GIDDENS, 1992, p. 73).

Simbólica e concretamente, os indivíduos contemporâneos parecem crescentemente protegidos contra as uniões que se pretendem estáveis. No plano da legislação, têm aumentado as conquistas no que diz respeito a essa proteção contra o outro vide as cada vez mais detalhadas cláusulas incorporadas aos registros civis de casamentos -, fornecendo-nos novo instrumental para lidarmos como o peso do passado - muito recentemente, passado a limpo - das enclausuradoras uniões de ontem. Mesmo munidos de leis, espécies de coletes a prova de contágios, paradoxalmente a sensação de que estamos cada vez mais desprotegidos não parece de nós se distanciar. Os recentes episódios de casamentosrelâmpago envolvendo membros do mundo das celebridades talvez nos forneçam algumas pistas para pensar esse cenário. 
Levando ao limite a banalização do divórcio, uniões como as que ocorreram entre a cantora pop norte-americana Britney Spears e seu amigo de infância, Janson Alexander, de apenas 55 horas $^{2}$, parecem apontar para uma perda de eficácia do dispositivo na manutenção das uniões. O ritual legal e burocrático da separação através do divórcio cada vez menos aparece como um obstáculo à separação; pelo contrário, parece uma garantia casar sem pensar duas vezes nem assumir os compromissos de praxe. E mesmo quando a cerimônia de casamento não chega a percorrer esse trâmite legal, não são raros os exemplos, se recorremos ao universo dos famosos, de casais que se separaram quase instantânea e efusivamente após se engajarem num projeto de vida comum. Saltam aos olhos, portanto, as novas (e surpreendentes) configurações atuais do casamento, até pouco tempo atrás tido de modo hegemônico como uma instituição quase “sagrada”, a que se aderia através de um cerimonial que demandava esforço e sacrifício por parte do casal. Configurações que, vale dizer, não se constituiriam senão em um contexto de crise, de reformulação das práticas e de reorganização das ideias e crenças.

\section{É preciso ser saudável}

Apesar de sua ambígua formulação inicial e ainda implícita, o casamento passa a ser vivenciado menos como um compromisso de duração eterna, do que como lugar de passagem a sustentar acordos de união permanentemente negociados. Constitui-se como parte de uma nova engrenagem de articulação dos relacionamentos amorosos, na medida em que, como lugar a que se acessa, suas portas de entrada e saída podem ser rapidamente percorridas, sem demandar (vultosos) gastos de tempo e de trabalho ou pactos assinados com fechaduras irreversíveis. Para, além disso, tem se tornado mais difícil duvidar da máxima, fartamente vendida em revistas semanais de informação e de divulgação científica através da fala de especialistas - estendida a todos os domínios da existência - de que é preciso estar em movimento para não adoecer ou não se desvalorizar. Nesse sentido, prorrogar a perder de vista o prazo de término das uniões amorosas na antiga forma do casamento aumentaria as

\footnotetext{
${ }^{2}$ Casamentos relâmpago. Famosidades. Disponível em:

<http://entretenimento.br.msn.com/famosos/casamentos-rel\%c3\%a2mpago?page=0> Acesso em: nov. 2011
} 
chances de um prejuízo para os indivíduos nele envolvidos em termos de uma determinada ideia de "saúde afetiva" e de cotação nos mercados da sociabilidade, na medida em que menos “arejados” e mais “desgastados” com o tempo. É como se os indivíduos fossem instados a estarem sempre atentos aos limites que separam a saúde da doença em suas vivências amorosas - mesmo que os métodos de aferição dessa suposta saúde não apareçam de forma objetiva -, seguindo a tendência crescente ao longo do século XX de incorporar explicações psicológicas para a gestão do eu (ILLOUZ, 2011). O discurso da saúde emerge, portanto, como um dispositivo regulador das ações e relações do eu, e ganha certa compatibilidade com as retóricas do mercado, dos investimentos e da capitalização.

Mas pode ser que, antes mesmo de se atentar para a qualidade dos tipos de enlaçamento das relações vivenciadas com o fim de averiguar os graus de saturação das proximidades e dos abismos amorosos, se responda a um impulso em direção à abertura. Não está a se dizer com isso que o fato de haver um discurso psicológico, quase onipresente, que mune os indivíduos de novos modos de gestão do eu ao estimular a produção de um saber sobre si e de uma fala consciente de si implique uma padronização das respostas ao discurso da saúde - mesmo sendo cada vez mais difícil não partir da premissa de que "a comunicação é a vida de qualquer relacionamento” (REDBOOK apud ILLOUZ, 2011, p. 52). São múltiplos os atravessamentos e um deles parece ser o de não se saber atravessado por esse discurso, mesmo quando as práticas de muitos indivíduos contemporâneos apontam para uma aversão aos sedentarismos do corpo e da alma. Cada um é suavemente convocado a desenvolver um consistente saber argumentativo e a incorporar como necessárias determinadas práticas ao ar livre que são incompatíveis com longas permanências na clausura, outrora habituais, mas agora sinalizadoras de fobias e desprazeres. Parece ser cada vez mais urgente a decisão de não suportar o que constrange o movimento e a buscar o que parece ir ao encontro dele, mesmo que esta última opção também implique novos tipos de riscos e sofrimentos.

Os casamentos-relâmpago das celebridades, por exemplo - apesar de por vezes nos causarem espanto ao constituírem o extremo de uma tendência de aceleração das rupturas e produção de novos enlaçamentos -, são cada vez menos estranhos a nós, que já os admitimos, em alguma medida, como possíveis e até mesmo inevitáveis. Seriam, portanto, uma variante nova do casamento tradicional, na qual o encurtamento assombroso de sua 
duração é seguido de um encompassamento social da prática como “casamento” em vez de outra coisa. Talvez até por não se ter elaborado coletivamente uma denominação capaz de dar conta dessa nova espécie de união; além disso, mesmo que apenas sob a forma do impulso, os indivíduos experimentam subir um degrau rumo à eternidade - pelo menos, a princípio, há uma vontade de casamento. É como se a vivência da experiência de casar, muitas vezes limitada apenas aos rituais de passagem que fazem os indivíduos mudarem o status social de solteiros para casados, sinalizasse para outro modo de apropriação do casamento contemporaneamente. A ambiguidade irromperia por uma indeterminação entre a vontade e a manutenção dela: quer-se saber o que é casar, mas sem casar. Mais surpreendente que essa nova modalidade de matrimônio efêmero, no entanto, é o abismo de sentido no qual os sujeitos contemporâneos são atirados ao terem que dar conta dos incômodos que a urgência do deslocamento constante e das adaptações em meio ao fluxo desperta nos corpos.

\section{Os abismos dos fluxos}

Ao mesmo tempo em que se demanda uma intermitente adaptação dos corpos contemporâneos aos ambientes de risco nos quais estão imersos, atraindo-o para as exterioridades e extremidades ${ }^{3}$, inclusive as de si mesmo, e um acompanhamento da vida no tempo em que (minimamente) a vida se dá os mal-estares advindos das perdas e separações não cessam de irromper e ameaçar a progressão do fluxo. As necessárias temporalidades das digestões para a amortização dos impactos e cortes abruptos, sem as quais seria inviável a vivência do/no risco, são negligenciadas em prol de um coletivo que não coloca em risco sua ilimitada expansão de saúde em função dos que já não tem saúde para acompanhar o ritmo “velhos”, “doentes”, ultrapassados de toda a sorte, “perdidos no tempo” e desconectados. Os que estão numa condição de “desvantagem temporal” têm que “correr atrás” do que foi perdido e do "prejuízo", sob pena de serem deixados à margem do processo de ganho crescente de saúde. Mas a ideia de saúde a que todos, de alguma forma, nos amarramos sobretudo através do consumo de publicações especializadas que nos ensinam a ter uma vida

\footnotetext{
${ }^{3}$ Os corpos são incitados a vivenciarem situações de risco, nos quais são assaltados por sensações-limites que abrem passagem para a constituição de respostas não previstas nas situações em que estão imersos. É como se os corpos estivessem permanentemente "à beira de si mesmos".
} 


\section{míDiA

saudável - não parece ser exatamente a que se vincula a um estado interior do corpo gerador de movimentos de expansão vital, mas a um estado ótimo, de tensão máxima dos músculos e das potências. No limite, trata-se de uma boa performance de saúde, capaz de garantir bons desempenhos físicos e mentais, pois “comportar-se de modo a exibir uma imagem saudável significa apresentar-se, a si e aos demais, como sujeito independente, responsável, confiável, dotado de vontade e autoestima” (BEZERRA, 2002, p. 235). As convocações oriundas das falas de especialistas, no sentido de que os indivíduos sejam capazes de viver de forma saudável, assumem conotações ambíguas ao serem “adaptadas” às suas rotinas de vida nas grandes cidades, em que o tempo disponível para a sustentação de práticas saudáveis é restrito: os indivíduos parecem incorporar o imperativo da (boa) saúde performando-se como saudáveis, o que implica, muitas vezes, apresentarem-se para si mesmos e para o mundo como imunes ou fortemente protegidos contra os perigos de doenças do corpo e da alma, a partir da adoção de alguns "roteiros de subjetividades saudáveis”.

E quando não podemos outra coisa a não ser padecer de dor e angústia, sentimo-nos piores por interrompermos o fluxo: haveremos de ficar para trás? A sensação de instabilidade que compartilhamos parece provir em parte da inescapável certeza de nos sabermos sós na interminável edificação de nosso eu (BEZERRA, 2002), no que diz respeito a todas as modalidades de relações vivenciadas e às atividades exercidas, com vistas a alcançar metas, superar etapas e vencer desafios. Ainda mais porque, muito sutilmente, reforça-se nossa ignorância com relação a nós mesmos; por exemplo, através dos discursos cientificistas que muitas vezes, e até implicitamente, nos destituem da possibilidade de inventar criativamente estratégias para viver a vida, que não sejam as prescritas pela medicina, pela biologia ou pela tecnologia. É preciso, antes, ser um consumidor voraz e perspicaz de tudo o que se produz de mais sofisticado em termos de conhecimentos especializados, implantando-os, em seguida, no corpo para que se extraia dele seu néctar de potência. Ao mesmo tempo, portanto, em que se estimula uma certa autonomia do sujeito, cria-se uma situação que favorece sua dependência em relação a ajudas especializadas. Trata-se de "uma autonomia assistida, fundada em um processo infinito de autoexame, autoregulação e autoaprimoramento e em uma demanda incessante de bens e serviços de apoio” (BEZERRA, 2002, p. 233). 


\section{Nós e as celebridades, as celebridades e os nós}

Há que se ressalvar, porém, o fato de os casamentos-relâmpago serem ainda vistos como um fenômeno mais ou menos circunscrito ao universo das celebridades, percebidas como habitantes de um microcosmo regido por leis próprias. Uma delas seria a do trânsito mais desinibido de sujeitos e corpos, na forma de múltiplas parcerias amorosas. Por mais que se identifique um processo em curso de flexibilização das práticas do casamento, tanto o encurtamento de sua duração como os rituais que o sucedem - de purificação e superação dos traumas - não deixam de causar certo estranhamento e gerar calorosos debates sociais. Sobrevive a certeza - através, muitas vezes, de mal-estares inexplicáveis sentidos no próprio corpo -, de que as coisas mudaram e estão mudando, e irão demandar a necessidade de produzirmos explicações que deem conta de nosso estado de ânimo superexcitado e perplexo. Será que não é assim que nos sentimos: perplexos? Diante de sensações desconfortáveis, preferimos, muitas vezes, acreditar que um fenômeno como o dos casamentos-relâmpago se circunscrevem ao universo das estrelas em vez de os incluirmos num cenário social mais amplo em que as relações têm se modificado radicalmente, e que envolve a todos os sujeitos contemporâneos. Não se trata de negarmos as singularidades constituintes do mundo da fama, que produz sem cessar rostos conhecidos, que habitam nossas casas, telas e vozes. Indivíduospersonagens que não nos conhecem, mas possuem passe-livre em nossas habitações e nos levam a manter com eles rituais de veneração, inspiração ou simplesmente conversação. Trata-se de enxergar e dar sentido à extensão das rachaduras sob nossos pés. Cabe também a pergunta: para além das singularidades constituintes desse universo, as celebridades não estariam em parte sendo percebidas como catalisadoras de certas transformações sociais, em função de mantermos nossa atenção voltada constantemente para elas?

Para além do tempo que utilizamos nos distraindo ou divertindo em plataformas midiáticas ocupadas por famosos (muitas vezes coocupadas por nós), cada vez mais somos informados do que se passa entre as quatro paredes dos cômodos por eles habitados, seja sob a forma de fotografias tiradas de modo espontâneo ou forçosamente extirpadas; ou, então, de falas que aludem ao gerenciamento da vida íntima levada a cabo por eles. De modo crescente, produz-se informação acerca de como conduzem suas relações pessoais e manejam a vida quando não estão “atuando”. À medida que aumentam em largura e quantidade as telas nas 
quais os famosos encenam-se publicamente, parecemos nos interessar pelo que está além (e talvez atrás) das telas, como se nos fosse possível, em alguma instância, depararmo-nos com o avesso dos personagens e acessarmos menos de como eles são para os outros e mais de como são para si mesmos. Se chegamos a uma aproximação mais íntima, conhecendo suas casas, seus gostos, suas manias e seus hobbies ou, mais do que isso, as estratégias de que lançam mão - envernizadas ou não com um viés aconselhador -, para lidarem relacionalmente com os outros, percebemos uma inclinação à performance. Essas vidas-atuações e personagens-deverdade, como nos sinaliza Paula Sibilia, em O show do eu, parecem se constituir como misturas não decantáveis de vida e performance. É como se não pudessem escapar de um dispositivo que os captura permanentemente para expô-los na visibilidade, mesmo quando não há câmeras por perto, apenas nossos próprios olhos, que os perseguem como se assombrados por alguma espécie de hipnose.

De qualquer modo, interessa-nos conhecer não só os filmes que estrelaram ou as canções que compuseram, mas o que fizeram e o que fazem o tempo todo, por onde e com quem circulam o que consomem etc. Assim, quem sabe, talvez nos inspiremos com suas formas desinibidas e “exemplares” de levar a vida. Parecemos estar sendo familiarizados com modelos, a nós apresentados didaticamente, por meio de um destrinchamento e devassamento de seus rituais cotidianos, de como gerenciar a vida. A todo o tempo, a partir de um acompanhamento intermitente de suas vidas, seguimos pistas sobre o que é preciso fazer para se aproximar desse modo glamouroso de viver, alternando-nos entre o que supostamente nos diz a ciência, entre outros discursos de viés aconselhador sobre os quais almejamos edificar nossas incertezas.

\section{Os casamentos-relâmpagos das celebridades}

Faz muito sentido, portanto, ficarmos a par de fenômenos como o dos casamentos-relâmpago, aparentemente restritos ao universo dos famosos, na medida em que nos atualizamos acerca de novas estratégias possíveis de como se lidar com os imprevistos, cada vez mais previsíveis, da vida contemporânea. A declaração de Sinead O’Connor, por 
exemplo, a respeito da decisão de desmanchar seu casamento com Barry Herridge ${ }^{4}$, após brevíssimas três horas de duração apontam-nos para um discurso bastante disseminado a respeito de um ideal de "amor livre", que nos impele a tomar decisões e a lançar mão de atitudes baseados em um compromisso com a liberdade - ideal que se afina com a "saúde afetiva” tão almejada e com as bases de sustentação dos relacionamentos contemporaneamente: emancipação, autonomia e igualdade (GIDDENS, 1992, p. 72): “Se você ama alguém, o liberte”. A frase de efeito simboliza uma era que repele todo tipo de eternidades temporais e espaciais, bem como uma forma de pensar e viver os relacionamentos íntimos que parece não mais caber em ambientes claustrofóbicos de quartos, casas e casamentos de antigamente. No entanto, a sentença pareceria menos contraditória se não tivesse sido dita após uma cerimônia em que o casal supostamente teria se unido por amor, muito semelhante àquelas que teriam ficado definitivamente obsoletas. Ao mesmo tempo, portanto, em que se identifica uma vontade de formar casais para estar juntos e compartilhar experiências, os parceiros amorosos parecem mais atentos às possíveis limitações impostas pelas uniões, munindo-se de estratégias para não se deixarem fechar por completo em ambientes em direção aos quais, em algum momento, parecem caminhar.

Na capa da revista Istoé Gente, de novembro de 2011, por exemplo, a atriz Danielle Winits aparecia em pose sensual, falando sobre o término de seu casamento de menos de três meses com o também ator Jonatas Faro. Na manchete, bem sugestiva, lia-se a seguinte frase: "Daniele Winits - livre para novas paixões". No interior da revista, respondendo a uma pergunta sobre seus casamentos, a atriz declarou que costuma se arrepender apenas daquilo que não fez:

Do que vivi são experiências, bagagem, felicidades adquiridas, cicatrizes às vezes. Nos meus dois casamentos, fui realizada como mãe e mulher. Deu mais certo do que para muita gente que continua casada. (...) Tanta gente que tem traumas. Eu não. (...) A gente está aqui para ser viver, ser feliz, esse é o intuito (WINITS, 2011, p. 47).

\footnotetext{
${ }^{4}$ Sinead O’Connor termina casamento após 16 dias, Gente Babado. Disponível em:

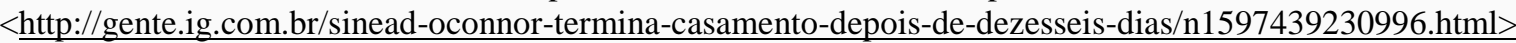
Acesso em: dez 2011
} 
Em seu discurso sobre a crença em um tipo de amor livre, sem amarras, que precisa ser vivido sob pena de que se comprometa sua felicidade, superando toda sorte de obrigação, contrato ou formalidade que o impeça de se realizar, Daniele Winits deixa transparecer uma nova moral que vem se construindo sobre o que é o amor e como deveria ser vivenciá-lo. Os compromissos a longo prazo - como o seu matrimônio anterior com o também ator Cássio Reis -, com quem esteve casada até iniciar um relacionamento com Jonatas Faro, não parecem ter pesado na sua escolha de viver um novo amor. O compromisso é, antes, com uma suposta autenticidade dos sentimentos e vontade de realização pessoal (TAYLOR, 2008) que levariam a uma flexibilização das regras. Afinal, regras parecem incompatíveis com a volubilidade dos “sentimentos” ou com a liberdade pessoal que assumimos como premissa pós-68. E urge expressá-los, em vez de reprimi-las, para que o corpo não envelheça precocemente e se feche em padrões limitados de ação, já que, como nos ensina certo discurso psicológico cada vez mais incorporado pelos indivíduos, existiria uma confluência entre os ideais contemporâneos de saúde e autorrealização (ILLOUZ, 2011, p. 68). Já não é mais interessante, portanto, manter os corpos docilmente obedientes e normalizados, à força de proibições, mas espertamente desobedientes, inclinados à ultrapassagem constante de barreiras e à implosão de paredes visando ao prazer, ao gozo e à felicidade ilimitada.

\section{As redes amorosas - e uma conclusão aberta}

Diferentemente do que postulavam as premissas do amor romântico, no entanto, a ênfase agora parece recair mais na intensidade da vivência amorosa do que na singularização do parceiro. Importaria menos a existência de um grande encontro entre duas almas, que se fundiriam para sempre em uma só, do que a possibilidade de transitar entre diversos encontros, à medida que os anteriores fossem “murchando”, “apagando-se”, perdendo viço e brilho. Como consequência dessa nova moralização, permanecer envolvidos em relacionamentos que parecem ter vencido seu prazo "natural” de validade tem se tornado cada vez mais difícil, em um momento em que “o tempo só parece responsável por despejar sobre 
nossos corpos uma porção de coisas indesejáveis” (SIBILIA, 2001, p. 7) e se exige atenção redobrada a todo o tipo de flacidez, do corpo e da alma ou da própria “vida como capital”.

Enquanto parecemos nos empenhar no exercício de nossas compatibilidades amorosas, testando as possibilidades - apresentadas como inesgotáveis - de conexões sexuais ou afetivas, uma nova conformação de relação começa a aparecer, mais antenada com o mundo à nossa volta do que com nossos abismos interiores. Mais do que a capacidade de dedicação, por anos a fio, a uma só pessoa escolhida entre muitas, o que parece atualmente em "alta” é a habilidade de sair de uma relação em direção a outra mais brilhosa ou “espetacular”, sem contaminações pegajosas ou lembranças doloridas que imponham um ritmo pouco veloz ao corpo, ou mesmo qualquer tipo de trauma que venha a se instalar em definitivo na alma, ameaçando a possibilidade irrestrita do movimento e da fluidez necessária à vida saudável.

Não basta fazer uma escolha única; é preciso escolher sempre, continuadamente, e cada vez melhor. Exercitar a habilidade de escolher, não escolhendo. E caso o corpo teime um encasulamento e se contraia em razão de superexcitações e hiperestimulações, que não tarde a se servir de um farto banquete de terapias à sua disposição, amenizando sua “dificuldade” adaptativa e sua nefasta resistência às mudanças. Resistir para quê? Não só não haveria mais perigo contra o qual se deveria estar protegido, mas seria preciso se lançar em direção a ele, ou melhor, a onde havia perigo e não há mais. O temido perigo de ontem parece sobreviver atualmente na pouco ameaçadora (e até estimulante) representação de um “obstáculo” que deve ser superado, vencido e quiçá até transformado em troféu. Os performáticos corpos de hoje são feitos de perigos enfrentados, marcas superadas e placares alcançados, sempre impulsionados rumo a novos desafios. E a contínua transposição dos limites leva menos a uma ponderação sobre as impossibilidades do que a uma vivência translimite, que apontaria, no limite, para a ausência dele.

Talvez uma boa forma de definir essas conexões seja através da metáfora da rede amorosa, com capacidade de expansão ilimitada e na qual se está ligado a muitos simultaneamente, mesmo que em um estado de latência. O trânsito constante entre um nó e outro e a impermanência definiriam esses novos modos de estar-agir no mundo, assim como a velocidade dos contatos e a possibilidade de manutenção paralela de várias relações. Nesse 


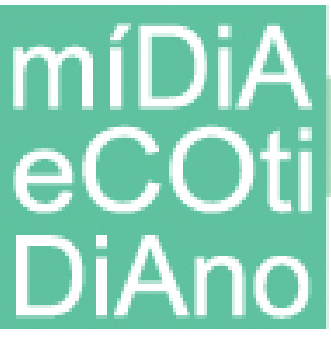

quadro, a falta de movimentação e o isolamento implicariam a dissolução da rede; por isso, é preciso não estar só. Ainda que a independência ou a autonomia sejam fatores fundamentais para os atores do jogo amoroso (GIDDENS, 1992), na medida em que permitem o trânsito livre e desimpedido rumo aos outros, é preciso estar sempre em contato, acionando e desligando os nós da rede, nunca eternamente, sempre provisoriamente e com o maior lucro de intensidade possível.

Os casamentos-relâmpago seriam, portanto, uma espécie de versão simbólica dos tipos de parcerias amorosas que passaram a vigorar contemporaneamente, em que é preciso afirmar e reafirmar a necessidade de se quebrarem todos os impedimentos inibidores do movimento e, estranhamente, afirmar a segurança de efetuar escolhas renovadas em meio à instabilidade do meio. A segurança de agora não é a de quem está protegido na blindagem do confinamento estável, mas a de quem não teme estar desprotegido. Afinal, não queremos ser apenas habitantes de nossas casas, feitas de paredes cada vez mais porosas, mas viajantes do mundo capazes de absorver e "curtir” toda sua diversidade. Quem sabe, construir casasmundo em que é possível ser um “turista” rotineiramente, e se sentir em casa mesmo que na condição de um passageiro.

\section{Referências}

BAUMAN, Zygmunt. Amor líquido. Sobre a fragilidade dos laços humanos. Rio de Janeiro: Zahar, 2004.

BEZERRA, Benilton. “O ocaso da interioridade e suas repercussões sobre a clínica”. In: PLASTINO (org.). Transgressões. Rio de Janeiro: Ed. Contracapa, 2002; p. 229-239.

GIDDENS, Anthony. A transformação da intimidade. Sexualidade, amor e erotismo nas sociedades modernas. São Paulo: Editora Unesp, 1992.

ILLOUZ, Eva. O amor nos tempos do capitalismo. Rio de Janeiro: Zahar, 2011.

SIBILIA, Paula. O show do eu: A intimidade como espetáculo. Rio de Janeiro: Nova Fronteira, 2008; p. 233-266. 
SIBILIA, Paula. "A moral da pele lisa e a censura midiática da velhice: O corpo velho como uma imagem com falhas”. In: GOLDENBERG, Mirian. Corpo, envelhecimento e felicidade. Rio de Janeiro: Ed. Civilização Brasieira, 2011; p. 83-108.

TAYLOR, Charles. Parte I, Capítulo 13: “A era da autenticidade”. Uma era secular. São Leopoldo: Ed. Unisinos, 2008.

\section{Revistas}

MAZZUCCO, Samia. Istoé gente. São Paulo: Ed. Três, n. 637, 28 nov 2011.

BARCELLOS, Luciana. Quem acontece. São Paulo: Ed. Globo, n. 573, 02 set 2011.

\section{Sites}

Casamentos relâmpago, Famosidades. Disponível em:

$<$ http://entretenimento.br.msn.com/famosos/casamentos-rel\%c3\%a2mpago?page=0 > Acesso em: nov 2011

Retrospectiva 2001: as separações do ano entre casais famosos, Gente Babado. Disponível em: $<$ http://gente.ig.com.br/retrospectiva-2011-as-separacoes-do-ano-entre-casaisfamosos/n1597413293453.html> Acesso em: dez 2011

Sinead O’Connor termina casamento depois de dezesseis dias, Gente Babado. Disponível em: $<$ http://gente.ig.com.br/sinead-oconnor-termina-casamento-depois-de-dezesseisdias/n1597439230996.html> Acesso em: dez 2011 